\title{
DIRETRIZES DO PROGRAMA NACIONAL DE EDUCAÇÃO PARA A PARTICIPAÇÃO EM SAÚDE
}

\section{DIRECTIVES OU PROGRAMME NATIONAL D'ÉDUCATION POUR LA PARTICIPATION EN SANTÉ}

Antonia Vasconcelos Martins ${ }^{1}$

MARTINS, A.V. Diret izes do Programa Nacional de Educação para a Participação em Saúde. Rev. Bras. Cresc. Des. Hum III(1): São Paulo, 1993

\section{RESUMO}

A Coordenação de Educação para a Saúde começou a nplantação de um plano de trabalho em mato de 1992. 0 modelo pedagógico EPPS permeia todos os projetos e ações da Coordenação, pois, espera-se com esse recurso estratégico desenvolver uma unidade conceitual metodológica acerca da 'educação para a Participação em Saúde” em todas as ações educativas do Ministério da Saúde.

\section{RÉSUMÉ}

La Coordination d'Éducation pour la Santé a Labute l'implantation d'un Plan de Travail en mal 1992. Le modèle pédagogique EPPS s 'insére dans tous les projets et actions de la Coordination, qui espere développer avec ce recours stratégique, une unité conceptuelle et méthodologique sur la question de 'l'Education pour la Participation eu Santé” dans lãs actions éducatives du Ministè^Aie de la Saúté.

1 Coordenação de Educação para a Saúde/COESA. Secretaria Nacional de Assistência à Saúde: Minislério da Saúde do Brasil Documento Sintese.

Coordination d’Éducation pour la Sante/COESA. Secratariat National à la Santé: Ministère de la Santé.

1 Mestre em Psicologia Social pela Universidade de Brasília, responsável pelo Projeto de Formação de Multiplicadores no Modelo Pedagógico da Educação para Panicipação em Saúde da Coordenação de Educação para a Saúde / SNAS/MS. End.: SAS Quadra 04 - Bloco N - $1^{\circ}$ andar - Brasília/DF - Brasil - CEP 70058-902. 


\section{1 - ANTECEDENTES}

A Educação em Saúde tem sido uma ação permanente dentro do Ministério da Saúde, embora com oscilações de enfoques e estratégias.

Em gestões anteriores deste $\mathrm{M}$ inistério, já se estruturaram ações de Educação para a Saúde. Em 1989, foram elaboradas as Diretrizes de Ação Educativa em Saúde pela Divisão Nacional de Educação em Saúde/DNES que, em vista do que preconiza o Sistema Unico de Saúde, pretendiam desenvolver um trabalho com profissionais de saúde numa concepção metodológica de ação participativa da população.

Do trabalho desenvolvido, até então, restou uma experiência nesse campo, caracterizada por projetos que se consolidaram através da participação da população, cuja realização se originou mais no ambito de iniciativas locais isoladas, do que propriamente como decorrência de uma diretriz nacional de governo.

Em 1990, em decorrência da reforma administrativa promovida pelo atual governo, a DNES foi extinta e na nova estrutura organizacional do Ministério da Saúde foi criado, em 1991, o Seniço de Educação para a Saúde do Departamento de Programas de Saúde vinculado à Secretaria Nacional de Assistência à Saúde (SNAS).

Em 1991, o Serviço de Educação para a Saúde realizou, como estratégia para avaliação da experiência em Educação para a Saúde, o Seminário internacional de Educa,cão para a Saúde, contando com a participação de consultores brasileiros e de outros países na área. Ainda, em 1991 foi criada a Coordenação de Educação para a Saúde através da Portaria Nr. 2301/91.

Com base em análises efetuadas e nos subsídios resultantes do Seminário internacional a Coordenação de Educação para Saúde, elaborou, na tentativa de retomar a Educação para a Saúde como um processo, as suas diretrizes gerais em perfeita sintonia com o que estabelece a Constituição, a Lei Organica de Saúde e o Plano Quinquenal de Saúde.

Como estratégia operacional básica desenvolveu-se o modelo pedagógico da Educação para a Participação em Saúde, cujos fundamentos funcionam como referencial teórico-pedagógico de todas as ações implementadas pela COESA.

\section{2 - O MODELO PEDAGÓGICO DA EPPS}

O Modelo Pedagógico da Educação para a Participação em Saúde -MPIEPPS proposto pela Coordenação de Educação para a Saúde/COESA é uma estratégia pedagógica que está sendo im- plantada nos piroga mas educativos do Ministério da Saúde, visando a adução de um marcc teórico unificado por parte dos técnicos envolvidos com essas açôes nó nível central, estadual e municipal. Assim sendo, o modelo pedagógica possui uma estrutura de conteúdos teóricos relacionados à Educação pará aParticipação em Saúde, abordando-as como processo educativo através de uma didáctica de apropriando do conhecimento. O modelo pedagógi co/EPPS destina-se à formação de multiplicadores nos três níveis $\mathrm{d} \wedge^{\wedge}$ ( Sistema de Saúde com o objetivo de desenvolver e fortalecer uma rede de atuação que se identifique com uma estrutura teórica e metodológica em suas açôes de saúde.

\section{1 - Marco Teórico do Modelo Pedagógico/EPPS}

Alguns conceitos são chaves nesse modelo pedagógico os qual guardam entre si uma coerência interna e uma relação de interdependên cia na sua articulação como um corpo teórico-metodológico. O que dá unidade ao modelo é a compreensão de saúde como um padrão dá existência humana relacionado à qualidade e compromisso com a vida não, simplesmente, à ausência de enfermidade.

A saúde concebida nesses termos descortina um horizonte mal amplo de relações e implicações referentes às causas das doenças, sua alternativas de cura e também sobre a condução do programa depreven ção por parte da Instituição. Entendida assim, a saúde passa a requere um enfrentamento novo, amplo, integrado e multidisciplinar para con trapor as ações desenvolvidas pelo setor, que em sua maioria se caracte rizam pela verticalidade do seu gerenciamento, pela descontinuidade pelo biologismo, pela desarticulação dos saberes, pela não participação da população e pela ausência de uma unidade conceitual por parte do executores dos programas de saúde.

Nesse sentido, a Educação para a Participação em Saúde integra um marco teórico que se baseia, principalmente, nos seguintes con ceitos:

\section{Educação para a Saúde como processo}

A Educação para a Participação em Saúde é um processo pedago gico que concebe o homem como sujeito, principal responsável por sul realidade. Como tal, as suas necessidades de saúde e bem-estar são solucionadas a partir de uma ação consciente e participante, a qual si organiza com elementos específicos de sua história, sua cultura e suá dinâmica própria. Como processo pedagógico, a Educação para a Participação em 
Saúde desenvolve recursos estratégicos facilitadores dessa organização. Instrumentaliza as populações para a identificação doí problemas de saúde, para a análise de suas causas e consequências, en rela,cão com suas práticas cotidianas, para o gerenciamento dos recursos pessoais e institucionais necessários à ado,cão de soluções especificas. A educação como processo se diferencia dos conceitos informação e comunicação porque enquanto a informação equivale à transmissão de uma mensagem sem retorno, na comunicação, a informação tem retorno. Educação como processo, por sua vez, promove a participação das pessoas no enfrentamento de seus problemas através da reflexão, da construção e apropriação do conhecimento sobre essa realidade e gera ações autogestionadas de solução.

Nesse sentido Educação para a Saúde como Processo baseia-se na ação-reflexão-ação em contato permanente com a experiência do sujeito.

\section{Participação}

E um processo gradual que se fundamenta na reflexão permanente da prática, ou seja, da experiência cotidiaoa das pessoas. Nas questões de saúde, a participação se processa pela reflexão sobre as ações de prevenção e promoção e na análise reflexiva acerca das doenças em toda sua amplitude de relações (biológicas, sociais, psicológicas, ambientais, institucionais). Essa participação aprofundasse através do diálogo de saberes (entre o saber médico e o saber da população) induz a construção e apropriação de um novo conhecimento. A participação em saúde inicia-se assim com a população enfrentando a realidade da saúde e da doença, atraí assando u na série evolutiva de estágios que vai da simples mobilização em torno de problemas pontuais até autogestão dos programas de saúde e de projetos de desenvolvimento local.

\section{Autogestão}

Entende-se como um nível elevado de consciência onde indivíduos e comunidades estão capacitados a assumir com autonomia a reflexão e a decisão das a,eões para intervir na realidade.

Autogestão não corresponde a autosuficiência utópica, onde a comunidade não precisa das Instituições; significa, sim, que a autogestão refletc a capacidade do sujeito c das comunidades para assumirem a condução dos processos de transformação de sua realidade de saúde em concordância com outros valores sociais. Nesta visão, instituições e comunidades assumem uma relação de contrapartida nos pro- jetos de saude tendo a população à frente de seu gerenciamento.

\section{Projeto de Vida}

É o objetivo do processo de educação, pois lhe dá uma direcionalidade. Todas as ações e intervenções no campo da saúde devem convergir para a realização bem sucedida de um projeto de vida. O projeto de vida das pessoas é um ideal ordcnador. Por isso é estruturante de todos os esforços implementados para transformar o quadro de doenças existentes. Nesse sentido o projeto de vida compreende três elementos:

A Qualidade de Vida: É o núcleo do processo educativo. Refereà capacidade do sujeito de transformar a prática em consciência através da reflexão permanente. Em outras palavras, o processo educativo pai a saúde precisa desenvolver a rcilcxão e a critica das pessoas sobre, doenças para que essa consciência possa gerar ações de mudança coa mais compromisso e responsabilidade.

Em outras palavras, a qualidade de vida se expressa em termos d consciência e do dc $\sim$ cnvolvimcnto da auto stima, da solidariedade, d participação, da organização, da cidadania.

Condições de Vida Refere-se aos fatores externos ao sujeito qu proporcionam seu bem-estar; alimentação, moradia, educação, saúd etc.

Nível de Vida: Relaciona-se com os recursos necessários para desenvolver as condições de vida, tais como: emprego, tecnologia, produção, etc.

Quando um processo educativo enfatiza transformações nas cor dições de vida da pessoa, corre o risco de que seus efeitos se restritas às mudanças da sua aparência.

Nesse sentido o modelo pcdagógico da Educação para a Participação em Saúdc integra concei ualrr ntc a qualidade, condições e nível d vida porque pressupõe em sua base teórica que 0 processo educativ somente gera transformações profundas quando o sujeito, a ser afetad em sua consciência, é capaz de provocar mudanças autogestionadas na condições c no Aval de vida.

Especificamente, nas qucstões de saúde, é necessário que a ações educativas abarquem essas dimensões da participação (com construção e apropriação do conhecimento) e da qualidade de vid (como expcriência de cidadania e consciência). Enquanto o trabalha de educação para a saúde enfatizar uma abordagem de transmissão de informação, pouco se conseguirá em termos do comprometimento da população com as açõcs preventivas e o cuidado com a vida. Somente quando a pessoa afetada em sua consciência passa a intervir nas causas das doenças e nas suas mani- 
festações de forma a alterar quadro de agravos de sua comunidade.

\section{2 - Didática de Apropriação do Conhecimento}

A didática de apropriação do conhecimento é uma parte fundamen tal c indissociável do modelo pedagógico/EPPS. É sua estrutura teórico metodológica que dá ao modelo uma dinâmica e uma identidade. Fundamcnta-sc na açãorcflcxão-ação, pois graças ao processo permanentc de reflexo sobre a rcalidadc, a população pode compreender seu problemas de saúde, construir coactivamente um conhecimento e aplica-lo na transformação dessa realidade. Para que o processo educativo cumpra essa função, a didática de apropiação do conhecimento realiza-se através de seis fases, interdependentes, que operam como um sistema, cujo objetivo é a transformação do sujeito e da realidade:

\section{$1^{a}$ Fase - Vivência}

Refere-se à prática das pessoas que se manifesta em suas experiencias, sua história e seu fazer. Toda vez que a população é solicitada a opinar sobre um problema específico sua explicação apoia-se na vivência; é o conhecimento empírico que retrata seu enfrentamento diante das situações e sua compreensão dos fenómenos ao seu redor. É o conhecimento do sentido comum, estruturado na interação de seus grupos e no seu contexto vivencial e cultural.

\section{$2^{a}$ Fase - Reflexão}

É a abstração da vivência para analisá-la em todas as suas implicações. Através da reflexão o conhecimento do sentido comum ultrapassa o nível micro, amplia-se e ascende ao nível científico. E através da reflexão que se passa do estágio de descrição do problema para chegar a uma análise mais qualitativa

À medida que um grupo de pessoas discute o problema da diarréia, por exemplo, e analisa suas relações com os problemas de alimentação, do saneamento, das informações disponíveis em sua comunidade, do emprego, etc, essas pessoas apropriam-se e constroem um novo conhecimento sobre a doença. Assim, o processo de reflexão leva ao conceito; nesse exemplo a reflexão conduz a um conceito de diarréia

\section{$3^{a}$ Fase- O Conceito}

É o resultado do processo de reflexão, portanto é uma sintese. Constitui a unidade de teoria e o fundamento de qualquer interpretação e explicação dos fenômenos. O conceito tem umpapel fundamental nesse modelo pedagógico porque concretiza a construção do conhecimento, sem a qual as comunidades não desenvolvem seu sentimento de "pertencimento" e autonomia. Sem essa conceitualização do problema ou do fenómeno em análise, a comunidade não pode instrumentalizarse para intervir na realidade em busca de suas soluções.

\section{$4^{a}$ Fase - Instrumentalização}

É a tradução do conceito em método de intervenção sobre a realidade. Quanto mais se repete sobre um problema mais fácil se torna encontrar o recurso pedagógico, financeiro ou operacional e outros, pala enfrentá-lo. Portanto, a instrumentalização da eficiência a ação do homem.

\section{$5^{a}$ Fase - Aplicação}

É a forma, através do método, como se intervém numa realidade para enfrentar um problema e transformá-lo. É a ação do homem, desta feita, fundamentada em conhecimento qualitativo e mais potente em sua força transformadora. Quando uma comunidade analisa e conceitua coletivamente o fenómeno da diarréia e desenvolve seus instrumentos para intervenção no problema, a aplicação desses recursos tem mais chance de ser efetiva.

\section{$6^{a}$ Fase - Recuperação}

O processo que engloba a vivência, a reflexão, o conceito, a instrumentalização e a aplicação gera um rol de experiências, resgata outras, diagnóstica a realidade. A recuperação crítica de experiências promovidas por essa trajetória pedagógica é uma condição para que haja construção do conhecimento. Sem ela não há avanço, não há caminho epistemológica, os processos morrem; ou seja, quando se aplica esse modelo pedagógico no enfrentamento de um problema de saúde, a população o aborda através dessas seis fases num movimento cíclico de suas experiências, retornando à novas vivências (que é sua relação cotidiana com os problemas); dessa feita, analisa c assume os problemas mais “sabida”, mais “dona” e mais fortalecida na compreensão de sua realidade. Todo esse processo participativo gera autonomia e amadurecimento na autogestão de seus projetos de vida.

\section{3 - A PROPOSTA DE TRABALHO DA COESA}

O modelo pedagógico/EPPS é uma opção filosófica e estratégica da COESA. Todas as suas ações se orientam pelo seu marco teórico e pela 
sua didática de apropriação do conhecimento. Em face das atribuições da COESA como instancia no nível nacional, duas estratégias são básicas no trabalho da coordenação:

- adoção de um marco conceitual unificado que seja assimilado por todos os integrantes do Sistema de Saúde;

- formação de uma equipe central de formadores que se encar-regará de repassar o mode- lo pedagógico numa rede crescente de multiplicadores até atingir estados, regiões e municípios.

Essas estratégias promoverão uma articulação com os Programas de Saúde e com as Secretarias Estaduais de Saúde. Nestas, estarão incluídas, em cada âmbito estadual as universidades, as empresas, as escolas e as organizações não govemarnentais. 